\title{
Is taste and smell impairment irreversible in COVID-19 patients?
}

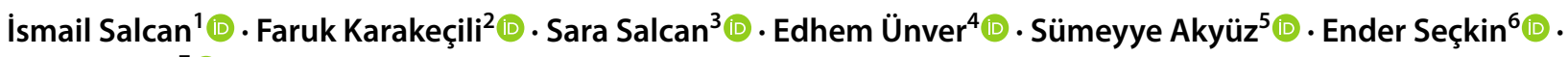 \\ Cemal Cingi ${ }^{7}$ (1)
}

Received: 14 October 2020 / Accepted: 10 December 2020 / Published online: 12 January 2021

(c) The Author(s), under exclusive licence to Springer-Verlag GmbH, DE part of Springer Nature 2021

\begin{abstract}
Objective It is known that the COVID-19 disease, which has affected the whole world, causes symptoms, such as cough, fever, shortness of breath, muscle pain, fatigue, diarrhea, headache and sore throat, in addition to various clinical findings, such as loss of smell and taste. In this study, we aimed to reveal the loss of sense of taste and smell in COVID-19 patients and to investigate whether these sensory losses are permanent in the healing process of the disease.

Method This prospective study included 94 COVID-19 patients. Smell and taste tests were applied to all patients. Ten days after the first test, a second test was applied to the patients with an impaired sense of smell to compare the results.

Results Of the 94 patients, 55.3\% were male, and the mean age was $53 \pm 19.6$ (21-90) years. There were 67 patients with smell and taste impairment, of whom 34 (50.7\%) had smell impairment only, 3 (4.4\%) had taste impairment only, and 30 (44.7\%) had both smell and taste impairment. It was found that the smell scores of 55 patients with smell and taste impairment in the first evaluation were significantly higher at the second measurement; and their tasting period was significantly shortened compared to the first measurement $\left(p^{<} 0.001\right)$.

Conclusion COVID-19 patients may present to medical centers with a broad variety signs and symptoms. This study shows that impairment in the senses of smell and taste is common in this disease and strongly associated with COVID-19 infection. However, smell and taste impairment is mostly temporary and improves during the recovery period.
\end{abstract}

Keywords COVID-19 $\cdot$ Smell test $\cdot$ Taste test $\cdot$ Prognosis

\section{Introduction}

The coronavirus disease 2019 (COVID-19) emerged in Wuhan city of China in December 2019 and rapidly spread as an atypical pneumonia pandemic with unknown causes

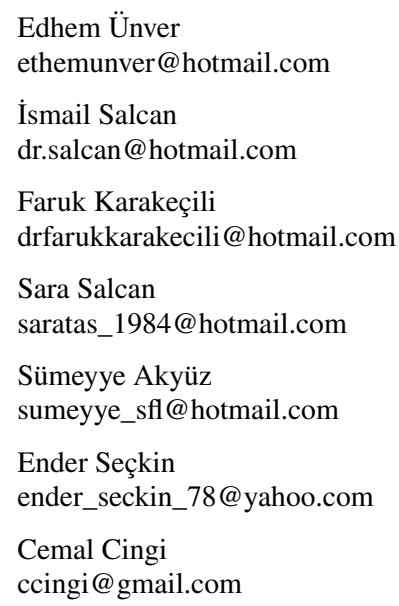

throughout the country within one month. On January 8, 2020, the Chinese Center for Disease Control and Prevention identified the causative pathogen of this disease as 2019$\mathrm{nCoV}$ [1]; however, later, this virus was officially named

1 Department of Otorhinolaryngology, Faculty of Medicine, Mengücek Training and Research Hospital, Erzincan Binali Yıldırım University, Erzincan, Turkey

2 Department of Infectious Diseases and Clinical Microbiology, Faculty of Medicine, Erzincan Binali Yıldırım University, Erzincan, Turkey

3 Department of Public Health, Faculty of Medicine, Erzincan Binali Yıldırım University, Erzincan, Turkey

4 Department of Chest Disease, Faculty of Medicine, Erzincan Binali Yıldırım University, Erzincan, Turkey

5 Department of Medical Microbiology, Faculty of Medicine, Erzincan Binali Yıldırım University, Erzincan, Turkey

6 Department of Otorhinolaryngology, Faculty of Medicine, Erzincan Binali Yıldırım University, Erzincan, Turkey

7 Department of Otorhinolaryngology, Faculty of Medicine, Eskişehir Osmangazi University, Eskisehir, Turkey 
as severe acute respiratory syndrome coronavirus-2 (SARSCoV-2) by the International Committee on Taxonomy of Viruses Coronavirus Study Group [2]. With the identification of the disease, infections have rapidly increased within a short period of time, and the disease exceeded regional limits, spreading globally. On January 30, 2020, the World Health Organization (WHO) announced this pneumonia as an epidemic threatening international public health, and declared it as a pandemic on March 11. Thus, the world has faced the greatest pandemic of the recent history, with a coronavirus being the cause of a pandemic for the first time in recorded history [3].

Coronaviruses $(\mathrm{CoV})$ are enveloped single-chain RNA viruses from the Coronaviridae family and have very rapid mutation and recombination abilities [4].The virus can cause a disease when it spreads from animals to humans while person-to-person transmission occurs by contact or the spread of droplets through sneezing/coughing [5]. The incubation period of COVID-19 ranges between 2 and 14 days (average 7 days) after the infection. The disease can be symptomatic or manifest as asymptomatic or mild respiratory tract infection. The disease can also manifest with a broad range of symptoms, such as muscle pain, fatigue, diarrhea, pneumonia, and severe acute respiratory tract infection $[6,7]$. In our clinical observations, some patients have complaints of taste and smell impairment in addition to these symptoms of the disease. In a study by Hjelmesæth and Skaare, it was reported that the patients experienced loss of smell and taste as the only symptom of SARS-CoV-2 infection [8]. Hendrik Streeck, a German virology professor, stated that at least two-thirds of all infected patients experienced loss of smell and taste [9]. Similarly, American otolaryngologists suggest that anosmia, hyposmia, and loss of taste must be included in the list of symptoms that will lead to COVID-19 suspicion in the lack of other explanatory conditions, and testing and isolation must be considered [10]. WHO also added loss of smell and taste to COVID-19 disease symptoms on May 4, 2020 [11]

The COVID-19 pandemic, affecting the entire world, has caused the deaths of many people during a relatively short, in addition to having negative social, economic and political outcomes. A certain treatment has not yet been defined for COVID-19 pandemic. It is necessary to carry out intensive studies on this disease in Turkey, as in the whole world. In our study, we investigated the disturbances in the sense of taste and smell in COVID-19 patients at first presentation. Then, we performed a second test after $10 \pm 2$ days in cases with persistent taste and smell disorders. Thus, we aimed to present the changes in the taste and smell senses of COVID19 patients over time.

\section{Materials and methods}

This study was prospectively carried out in the ear-nosethroat department of Erzincan Binali Yıldırım University Faculty of Medicine. This center has been designated by the Turkish government as a pandemic hospital to treat COVID-19 patients. The study included in-patients who were positive for COVID-19 according to the polymerase chain reaction (PCR) test between May 1 and June 20, 2020. The study was carried out in accordance with the principles of Declaration of Helsinki. Ethical approval was obtained from the Clinical Research Ethics Committee of Erzincan University (decision no. 05/22), as well as approval from the Turkish Ministry of Health (scientific research no. 2020-04-29T15_22_34).

Ninety-four COVID-19 patients were included in the study. Smell and taste tests were applied to all patients at first presentation. Ten days later, a second test was applied to the patients with impaired senses of smell to compare the results. Our study did not include patients who were taken into intensive care and intubated or those with a history of cerebral events.

\section{Smell test}

The psychophysical test of smell function was performed using Sniffin' Sticks test with commercially available felttip pens (Sniffin 'Sticks, Burghart GmbH, Wedel, Germany) $[12,13]$. For smell presentation, the cap of the pen was removed by the experimenter for approximately $3 \mathrm{~s}$, and the tip of the pen was placed approximately $1-2 \mathrm{~cm}$ in front of the patient's nostrils. Smell definition was evaluated using 16 common smells. The participants were asked to choose from a list of four possible definitive terms for each smell. Each smell compound was presented by the experimenter, and a pause of at least $30 \mathrm{~s}$ was provided to prevent desensitization to smell. The participants were free to sample the smells for durations required to make a decision. Test result was recorded as the total score of accurately identified smells [12, 13].

\section{Taste test}

This test included the description of four solutions in water representing different types of taste. Four taste variables were prepared as follows: $50 \%$ sucrose for sweet taste, $0.9 \%$ saline solution for salty taste, $4.2 \%$ vinegar solution for sour taste, and $20 \%$ coffee solution (sugar free) for bitter taste [14]. The study was conducted during morning hours (9 
a.m. -11 a.m.) to eliminate bias in the results due to circadian variation, and the participants were asked to avoid eating and drinking $1 \mathrm{~h}$ before the appointment. After rinsing their mouths with distilled water, the participants were given a chronometer to hold in their right hands to record the taste definition duration. Four essential flavors; i.e., sweet, salty, sour and bitter aqueous solutions were provided on paper strips at equal dimension and shape. The taste strips were placed on the front two-third of the tongue dorsum. After placing the strips, the taste recognition period (in seconds) measured by the participants was recorded for each flavor. The participants were asked to rinse their mouths thoroughly between the tests of each sample [14].

\section{Statistical analysis}

IBM SPSS v. 21.0 for Windows was used for the statistical analysis of the data. The Kolmogorov-Smirnov normality test was used to examine whether variables were distributed normally. Since the measurement results obtained did not indicate a normal distribution, the non-parametric Mann-Whitney $U$ test and Wilcoxon test was used. Numbers (percentages) and median (Q1; Q3) values were used to summarize the data. $p<0.05$ was accepted as statistically significant.

\section{Results}

Of the 94 COVID-19 patients included in the study, 55.3\% $(n=52)$ were male and $44.7 \%(n=42)$ were female, with the mean age being determined as $53 \pm 19.6(21-90)$ years. The smell and taste test results are given in Table 1, and accordingly smell and taste impairment was present in 67 (71.2\%) patients, of whom 34 (50.7\%) had a smell disorder only, $3(4.4 \%)$ had a taste disorder only, and $30(44.7 \%)$

Table 1 Smell and taste test results at the first evaluation

\begin{tabular}{|c|c|c|c|c|}
\hline & \multicolumn{2}{|c|}{ Study group $n=94$} & \multicolumn{2}{|c|}{$\begin{array}{l}\text { Patients with smell and } \\
\text { taste problems } n=67\end{array}$} \\
\hline & Median & (IQR) & Median & (IQR) \\
\hline Smell & $7 *$ & $6.0-9.0$ & $7 *$ & $6.0-8.0$ \\
\hline \multicolumn{5}{|l|}{ Taste } \\
\hline Sweet & 12.7 & $4.9-18.7$ & 14 & $6.0-19.2$ \\
\hline Salty & 14.2 & $5.4-17.3$ & 14.2 & $6.5-17.8$ \\
\hline Sour & 14.5 & $6.0-18.3$ & 15.4 & $6.1-19.6$ \\
\hline Bitter & 12.3 & $4.6-17.6$ & 12.7 & $5.0-17.9$ \\
\hline
\end{tabular}

$I Q R$ Inter-Quartile range

*As the distribution of the group is not normal, Wilcoxon Test was used to analyze the data and the mean value (7) is used instead of the average had both smell and taste disorders. Thirty-four (50.7\%) of the patients with smell and taste disorders were male and 33 were female $(49.3 \%)$, and their mean age was $55.7 \pm 19.8(21-90)$ years. There was no significant difference in the taste and smell scores by gender $(p>0.05)$ (Table 2).

Sixty-seven patients with smell and taste impairment were included in the second evaluation $10 \pm 2$ days after the first test. At this stage, the taste and smell tests were applied to a total of 55 patients since four patients had died. Five patients were in intensive care and three patients could not be contacted.

The smell and taste test results for the second evaluation are given in Table 3. It was found that the smell scores of the patients with smell and taste impairment in the first evaluation were significantly increased at the second measurement and their tasting period was significantly shortened compared to the first taste test $(p<0.001)$. As a result of these measurements. It was determined that the smelling complaint persisted in only 3 (5.4\%) patients.

Table 2 Smell and taste scores of the patients according to gender

\begin{tabular}{lllllll}
\hline & \multicolumn{2}{l}{ Male } & & & Female & $p$ \\
\cline { 2 - 3 } & Median & $(\mathrm{IQR})$ & & Median & $(\mathrm{IQR})$ & \\
\hline Smell & 7 & $6.0-9.0$ & 7 & $6.0-9.0$ & 0.19 \\
Taste & & & & & \\
Sweet & 13.8 & $6.4-18.6$ & & 12.2 & $4.4-19.3$ & 0.61 \\
Salty & 13.4 & $6.5-16.7$ & & 13.4 & $3.7-17.6$ & 0.98 \\
Sour & 13.8 & $5.3-17.3$ & & 15.5 & $6.0-21.5$ & 0.18 \\
Bitter & 12.3 & $4.2-17.9$ & & 12.3 & $5.0-16.6$ & 0.81 \\
\hline
\end{tabular}

IQR:Inter-Quartile Range

*As the distribution of the group is not normal, Wilcoxon Test was used to analyze the data and the mean value (7) is used instead of the average

Table 3 Results of the first and second tests of the patients presenting with smell and taste impairment

\begin{tabular}{lllllll}
\hline & \multicolumn{2}{l}{ First evaluation } & & \multicolumn{2}{l}{ Second evaluation } & $p$ \\
& Median & $(\mathrm{IQR})$ & & Median & $(\mathrm{IQR})$ & \\
\hline Smell & $7 *$ & $5.2-8.0$ & & 8 & $7.0-9.0$ & $<0.001$ \\
Taste & & & & & \\
Sweet & 13.7 & $4.7-19.5$ & 5.5 & $3.2-11.7$ & $<0.001$ \\
Salty & 13.4 & $5.0-17.8$ & 5 & $3.0-10.0$ & $<0.001$ \\
Sour & 15 & $6.0-17.7$ & 4 & $1.0-10.0$ & $<0.001$ \\
Bitter & 13.4 & $4.7-17.9$ & 6 & $3.0-10.0$ & $<0.001$ \\
\hline
\end{tabular}

IQR: Inter-Quartile Range

*As the distribution of the group is not normal, Wilcoxon Test was used to analyze the data and the mean value (7) is used instead of the average 


\section{Discussion}

The COVID-19 pandemic is an urgent health condition affecting the whole world, as in all pandemics. Health care systems must create a rapid response against this disease. Revealing the signs and symptoms of the disease is important in terms of early treatment since it is caused by a new virus about which we have limited knowledge. There are no specific clinical symptoms which can clearly distinguish COVID-19 from other viral respiratory tract infections. After the outbreak of the pandemic, many authors reported that COVID-19 patients had a high rate of smell and taste problems [15-17]. While it is known that other viruses such as influenza also show this symptom. It has been reported that every contact in COVID-19 infection presents a measurable impairment of smell [18]. In a study conducted by Beltrán-Corbellini et al., new smell and taste impairment was observed at a significantly higher rate in COVID-19 patients compared to influenza cases [19]. These symptoms can be observed especially during the early stages of the disease or they can be the only clinical symptoms of the disease $[15,16]$. Angiotensin converter enzyme 2 (ACE-2) receptors are commonly found in oral mucosa and nasal mucosa epithelium cells. It has been reported that ACE- 2 receptors play an essential role in the transfer of SARS-CoV-2 to the main host cell and the mechanism causing smell and taste impairment was related to this condition $[20,21]$. The current study was planned as qualitative research to measure the smell and taste functions of patients diagnosed with COVID-19 to explain the relationship between the disease and impairment in these senses and investigate the change in these senses in the course of the disease. We found that 67 of the 94 patients (71.2\%) had loss of smell or taste. of whom $34(50.7 \%)$ had smell impairment only 3 (4.4\%) had taste impairment only. and $30(44.7 \%)$ had both smell and taste impairment. In a study conducted in Iran. Moein et al. reported that 35\% of COVID-19 patients had loss of smell or taste. In the same study, the authors determined that $12 \%$ of patients experienced loss of smell only. $7 \%$ experienced loss of taste only and $17 \%$ experienced loss of both senses [18]. The rates of in that study are lower than our results which may be associated with the differences in the test methods used. In a survey study conducted with COVID-19 patients in Italy, approximately $34 \%$ of patients reported loss of smell or taste [17]. The rates reported in that study are also lower than our rates. However, the previous authors' account of the loss of smell and taste was solely based on the statements of the patients in contrast to measurements performed in our study. In another study undertaken by Altin et al. in Turkey. $67.1 \%$ of patients had loss of smell or taste. $35.8 \%$ had loss of smell only. $1 \%$ had loss of taste only and $24.6 \%$ had loss of both smell and taste [22] which is consistent with our results.

Another study in Iran showed that women's smell scores were better, if not significantly different, than men (17. 18). Similar to the later work we did not observe statistically significant differences in smell and taste impairment between the male and female COVID-19 patients.

In studies conducted to date, COVID-19 patients and healthy individuals have been compared in terms of smell and taste impairment $[18,22]$. It has been reported that COVID-19 patients have significantly higher smell and taste impairment. In our study, healthy individuals were not included in the sample as a control group. A study group consisting of only COVID-19 patients was examined in terms of their smell and taste functions at first presentations compared to a second evaluation undertaken on average 10 days later. According to the second test results, existing smell and taste impairment had decreased significantly. Although the literature contains studies related to the loss of smell and taste in COVID-19 patients, our study is the first to examine how these complaints of the patients changed in the acute and recovery periods of the disease. In this aspect, we consider that our study is original and our data will contribute to the literature.

\section{Conclusion}

COVID-19 patients present to medical institutions with a broad variety signs and symptoms. It has been found that impairment in the senses of smell and taste is common in this disease and they are strongly associated with the COVID-19 infection. The results obtained in our study support that smell and taste impairment is very common especially in the acute period of the disease and this is a reliable indicator of the disease. In addition, we determined that smell and taste impairment was mostly temporary and improved during the recovery period. However, considering that there are many unknown aspects of the disease it has not yet been elucidated whether this impairment is permanent. There is a need for more detailed, multi-centered and long-term studies with a higher number of more patients on this subject. The results of our study support that identification of infected patients who do not have any particular symptom other than smell and taste impairment is very important in terms of measures to be taken to prevent the transmission of the disease to uninfected people.

Author contributions İS, SS, and FK made substantial contributions to the conception and design of the study acquisition and data analysis and 
drafting of the manuscript. SS, EÜ, SA, ES made substantial contributions to data interpretation and critical revision of the manuscript for important intellectual contents. $\mathrm{CC}$ had contributed to the conception and design of the study, then he made the final revision. All authors read and approved the final manuscript.

Funding This research did not receive any specific grant from funding agencies in the public. commercial or not-for-profit sectors.

\section{Compliance with ethical standards}

Conflict of interest The authors declare that they have no conflict of interest.

Ethics approval The study was performed in accordance with the ethical standards as laid down in the 1964 Declaration of Helsinki and its later amendments.

Consent to participate Written informed consent was obtained from all individual participants included in the study.

Consent for publication Full consent to publish deidentified data was obtained by all patients.

\section{References}

1. Lu R, Zhao X, Li J, Niu P, Yang B, Wu H, Wang W, Song H, Huang B, Zhu N (2020) Genomic characterisation and epidemiology of 2019 novel coronavirus: implications for virus origins and receptor binding. The Lancet 395(10224):565-574

2. Gorbalenya AE, Baker SC, Baric R, Groot RJd, Drosten C, Gulyaeva AA, Haagmans BL, Lauber C, Leontovich AM, Neuman BW (2020) Severe acute respiratory syndrome-related coronavirus: The species and its viruses-a statement of the Coronavirus Study Group. bioRxiv 2020.02.07.937862. https://doi. org/10.1101/2020.02.07.937862

3. WHO (2020) Coronavirus disease 2019 (COVID-19). Situation report 52. https://www.who.int/emergencies/diseases/novel-coron avirus-2019/situation-reports. (Accessed 12 Nov 2020)

4. Lu Q, Shi Y (2020) Coronavirus disease (COVID-19) and neonate: What neonatologist need to know. J Med Virol 92(6):564-567

5. Özdemir Ö, Pala A (2020) Çocuklarda Covid-19 enfeksiyonunun tanısı, tedavisi ve korunma yolları. J Biotechnol Strategic Health Res 1:14-21

6. Jiang F, Deng L, Zhang L, Cai Y, Cheung CW, Xia Z (2020) Review of the clinical characteristics of coronavirus disease 2019 (COVID-19). J General Int Med 5:1-5

7. Zhang R, Wang X, Ni L, Di X, Ma B, Niu S, Liu C, Reiter RJ (2020) COVID-19: Melatonin as a potential adjuvant treatment. Life Sci 4:117583

8. Hjelmesæth J, Skaare D (2020) Loss of smell or taste as the only symptom of COVID-19. Tidsskrift for Den norske legeforening (2020)

9. PP. S (2020) Wir haben neue Symptome entdeckt". Frankfurter Allgemeine. https://www.faz.net/aktuell/gesellschaft/gesundheit /coronavirus/neue-corona-symptome-entdeckt-virologe-hendrikstreeck-zum-virus-16681450.html. (Accessed 12 Nov 2020)
10. AAO-HNS (2020) Anosmia, Hyposmia, and Dysgeusia Symptoms of Coronavirus Disease. . https://www.entnet.org/content/aao-hnsanosmia-hyposmia-and-dysgeusia-symptoms-coronavirus-disea se. (Accessed 12 Nov 2020)

11. WHO (2020) Q\&A on coronaviruses (COVID-19). https://www. who.int/emergencies/diseases/novel-coronavirus-2019/questionand-answers-hub/q-a-detail/q-a-coronaviruses. (Accessed $12 \mathrm{Nov}$ 2020)

12. Hummel T, Sekinger B, Wolf SR, Pauli E, Kobal G (1997) 'Sniffin'sticks', olfactory performance assessed by the combined testing of odor identification, odor discrimination and olfactory threshold.' Chem Senses 22(1):39-52

13. Kobal G, Klimek L, Wolfensberger M, Gudziol H, Temmel A, Owen C, Seeber H, Pauli E, Hummel T (2000) Multicenter investigation of 1,036 subjects using a standardized method for the assessment of olfactory function combining tests of odor identification, odor discrimination, and olfactory thresholds. Eur Arch Otorhinolaryngol 257(4):205-211

14. Kale YS, Vibhute N, Belgaumi U, Kadashetti V, Bommanavar S, Kamate W (2019) Effect of using tobacco on taste perception. J Family Med Primary Care 8(8):2699

15. Vaira LA, Salzano G, Deiana G, De Riu G (2020) Anosmia and Ageusia: common findings in COVID-19 patients. Laryngoscope. 130(7):1787. https://doi.org/10.1002/lary.28692

16. Gane SB, Kelly C, Hopkins C (2020) Isolated sudden onset anosmia in COVID-19 infection. A novel syndrome. Rhinology 10:7

17. Giacomelli A, Pezzati L, Conti F, Bernacchia D, Siano M, Oreni L, Rusconi S, Gervasoni C, Ridolfo AL, Rizzardini G (2020) Selfreported olfactory and taste disorders in patients with severe acute respiratory coronavirus 2 infection: a cross-sectional study. Clin Infect Dis. 71(15):889-90. https://doi.org/10.1093/cid/ciaa330

18. Moein S, Hashemian S, Mansourafshar B, Khorram-Tousi A, Tabarsi P (2020) Doty R Smell dysfunction: a biomarker for COVID-19. Int Forum Allergy Rhinol. 10(8):944-950. https:// doi.org/10.1002/alr.22587

19. Beltrán-Corbellini Á, Chico-García JL, Martínez-Poles J, Rodríguez-Jorge F, Natera-Villalba E, Gómez-Corral J, Gómez-López A, Monreal E, Parra-Díaz P, Cortés-Cuevas JL (2020) Acute-onset smell and taste disorders in the context of COVID-19: a pilot multicentre polymerase chain reaction based case-control study. Eur J Neurol. 27(9):1738-1741. https://doi.org/10.1111/ene.14273

20. Wu C, Zheng M (2020) Single-cell RNA expression profiling shows that ACE2, the putative receptor of Wuhan 2019-nCoV, has significant expression in the nasal, mouth, lung and colon tissues, and tends to be co-expressed with HLA-DRB1 in the four tissues. 2020020247

21. Xu H, Zhong L, Deng J, Peng J, Dan H, Zeng X, Li T, Chen Q (2020) High expression of ACE2 receptor of 2019-nCoV on the epithelial cells of oral mucosa. Internat J Oral Sci 12(1):1-5

22. Altin F, Cingi C, Uzun T, Bal C (2020) Olfactory and gustatory abnormalities in COVID-19 cases. Eur Arch Oto-Rhino-Laryngol $5: 1-7$

Publisher's Note Springer Nature remains neutral with regard to jurisdictional claims in published maps and institutional affiliations. 